\title{
Youth Tourism as Appropriation of the World: A Psychological Perspective
}

\section{Rainer Schönhammer}

University of Munich

In commonsense understanding of growing up this goes without saying: the travels of youth tourists are somehow part of the transition to adulthood. Insights into the psychic dimensions of this process are provided by descriptions and reflections of novelists. The first German novel with the subtitle "a psychological novel," which appeared in the second half of the 18th century, reflects the importance of travel for the hero's relation to the world, and it does this in the hero's name, which is also the title of the novel: Anton Reiser (Anthony the Traveler). Karl Philipp Moritz, the author, was the editor of one of the first German psychological periodicals.

For most of the developmental psychologists of the 20th century the topic travel seems to have been too mundane. One of the exceptions was Lewin. Lewin thought of the psychic life in spatial concepts: life space with more or less structured regions, paths, boundaries, and locomotions (Lewin, 1935; 1951). His theory, which conceptualized the inner life in spatial metaphors, kept in mind the literal meaning of life space and, especially important for the topic of this article, "the region of free movement" with its changing shape and importance during childhood, adolescence, and adulthood.

The findings of the research on youth tourism reported here make sense as an expression of the adolescent drive to expand the region of free movement. The widening of the life space in youth tourism involves not only hitherto unknown geographical areas, but also unknown, strange social situations. A rough schema of the typical life space of adolescents will help us to understand the topology of youth tourism. (It should be noted that Lewinian concepts are adopted here only for the sake of describing behavior and inner dynamics; the mathematical implications of Lewin's "topology" are disregarded.)

\section{Adolescent Life Space}

The life space of an adolescent typically includes two large regions with strong adult control: family and school/work. Areas with a greater amount of free movement are the overlapping regions of leisure activities and peer group life. Independent physical mobility, for example, riding one's own bike, provides in later childhood a possibility to escape 
periodically from the control of adults and to appropriate at the same time the world beyond the familiar life space. Adolescents make a ritualistic use of motorcycles and cars to assure themselves of their expanding region of free movement (cf. Goldberg, 1969; Csikszentmihalyi \& Larson, 1984; Schönhammer, 1991).

Of course, the permeability of the boundaries between the different regions within the life space and of the boundary to the "outer" world, that is, to unknown/strange places or situations, is not the same for all (cultural, national, social) groups of adolescents. These differences and those of gender and individual personality are bracketed here. This will help to understand what youth tourism typically means for adolescent life space.

It is useful to distinguish between three forms of juvenile tourism: travel with the family; organized youth tourism; and, finally, unorganized youth tourism. Adolescents touring with their family may experience their situation as even more childish than that of their everyday life: family life rules the day. For adults/parents this is a well-known source of holiday stress. Adolescent members of the family often become homesick for their peer group. Organized youth tourism provides new peers, perhaps even from different nations. But there are adult officials, and typically only a small range of independent mobility is permitted. Unorganized youth tourism leaves behind all forms of adult control: independent mobility beyond the boundary of known familiar places and social situations is possible now. The price for this unusual freedom is a loss of physical and social security.

\section{Exploration of Unorganized Youth Tourism}

Two investigations (one in youth hostels and one in railway stations and on trains) were undertaken to determine how young backpack tourists in Europe experience the freedom of unorganized youth tourism.

Youth hostels. In the first study, carried out in 1984, visitors to Bavarian youth hostels (in Munich and in Prien) were asked to write compositions on "Encounters with people from foreign nations and cultures: personal experiences." In addition, partly prestructured interviews were conducted on the same topic. Altogether 64 compositions of young tourists from 11 European and overseas countries-most of them written in English-were gathered, and 70 travelers were interviewed. The material was analyzed by means of qualitative content analysis. The detailed report on the investigation (Schönhammer, 1987) makes reference to a number of sources in English.

In what follows, essential features of the reported experiences are presented and briefly illustrated. 


\section{The International Peer Group}

Some of the young travelers express a deep fascination, while other young tourists depict their travel encounters with (ironically!) distance as somehow boring. A few examples illustrate these different evaluations. A male British traveler writes:

Although traveling alone, I have never spent one minute without companionship of some kind: in trains, buses, ships, railway and bus stations; but above all, youth hostels have provided me with friends and conversation from all corners of the world.

Youth hostels have matured my mind, they have shown me many nationalities operating together under one roof, something that could perhaps be given to the United Nations as something to work on-or at least to show how far from reality they are.

A female Canadian student also appreciates the possibility of meeting people in youth hostels:

I do find that one of the best ways to meet people while traveling is by staying in youth hostels. Nowhere else do you meet people not only from the country in which you are staying but also from the four corners of the Earth. And nowhere else do you meet people so open to meeting others. Although I have not had long to spend in each place, I feel that I have met some really special people, several of whom I will keep in touch with and who knows, next time, if I make it to Sweden or Australia, I might find a friendly face waiting to meet me; not to mention the amazing number of new Canadian friends I have made. Whether traveling alone or with friends, there is nothing more special than sharing a part of your journey with a new friend. After all, it is not only the countries that we want to see when we travel, it is especially the people.

The following remarks of a British girl express a comparatively sober view of the encounters:

Too often when one meets people in trains or stations, the conversation rarely exceeds the bounds of: "Where do you live? What do you do? Where have you been and where are you going?" and I must admit that on some occasions I really can't be bothered to muster interest in the curriculum vitae of someone I'll never see again in my life. But constantly there is a rapport between fellow travelers that allows me to strike up a conversation with other, young people: far more easily perhaps than one could in one's own country. Some days nearly all the people you meet seem to be "inter-railing" their way around Europe.

It's not only interesting but also very useful to be able to exchange tips and information or swap experiences with other people. There's almost a feeling of solidarity - "We are all in this together: for better or for worse." But although informative and educational, the conversation is almost always purely factual, which means at the end of an hour or two one still scarcely knows them any better. Despite the fact that the swapping of ad- 
dresses is common practice, I rarely feel inclined to keep up a correspondence with someone I only met for a day.

Whether fascinated or sober, most of the compositions state that the "encounters with people from foreign nations and cultures" in general consist of conversations with other young tourists. The backpackers traveling across Europe in summertime seem to constitute a tremendous international peer group. The "feeling of solidarity" within this group can be understood as a way of coping with the ambivalence of free movement in strange space. The strange is dialectically transformed into familiarity. How does this work? The "trick" of this magic transformation (as expressed by "feeling of solidarity") is a kind of emotional resonance: mutual empathy for the affective ambivalence of freedom.

Those who have experienced this situation a number of times tend to express a more sober, discriminating view. They critically reflect that the life space of youth tourists is somehow "extraterritorial" in relation to the visited foreign countries, and the constant repetition of the international peer group's small talk bores them.

\section{Language Barriers}

A closer look at the communication within the international peer groups has to take into account the language barrier. Of course, some of the young tourists speak foreign languages quite well. For them, the conversation with fellow travelers may be a welcome opportunity to prove their skill. But fluent conversations between travelers with different native languages are an exception. The experience of limited conversations is often described. A male American writes:

The youth hostels are also excellent places to meet people, as everyone there is a traveler, anxious to meet people just like you.

One night in the hostel in Amsterdam I met two girls from Lyons, France, who spoke a bit of English. I speak a bit of French. For a couple of hours we talked, some French, some English, but it was hard to keep a conversation going or to learn a lot because our vocabularies were so small and we were limited in what we could talk about.

This obviously, isn't a problem with people who speak English, and I have had wonderful times together with people from Canada, England, New Zealand, Australia, and South Africa. It seems the most important aspects of meeting people are to be warm, friendly, lively, and curious. Because even if you can't speak much together, it's still very possible to just enjoy being together. And laughter and smiles are the same in every language.

Being "anxious to meet people like you," the young travelers manage to communicate "even if you can't speak much together." As a male British student puts it: 
In the various hostels we have visited we have talked to numbers of people without use of common language between us. Different people would translate to the different groups, conveying what each person wanted to say to the others. What did "bind" us together was a common interest in travel, seeing different places and meeting different people. With this just being my first trip it has surprised me how easily people from so many nations can come together and communicate. Even if the people have to resort to a form of sign language with words added here and there, if there is a want, people will manage to communicate.

Mutual empathy becomes necessary in a technical sense if the young travelers want to maintain communication beyond the language barrier. The effort to communicate nonverbally thus may involve a deepening of emotional resonance. The language barrier is sometimes described as a chance for encounters of an especially vivid character to occur. A female American student states:

A smile, I have found, means more than a thousand words, and can easily replace them. Even when the hand signals, drawn pictures, animal imitations and futile attempts to understand fragments of foreign language fail, a smile and the universal shrug of the shoulders can make everybody laugh, at which point, communication can be considered sufficient, because in no time at all, you can feel close to these new friends. I feel more confident in Europe, now that I've been successful at meeting friends by using an "international language" of body motions and facial expressions. And I'm sure that all those who have communicated by utilizing this "international language" will argue that it requires time and patience, but all energy spent will be worth it, and the memories of times spent communicating with the people of foreign countries will outlast any souvenir that could be purchased.

A male fellow countryman adds:

Granted, verbal communication is quicker and more thorough if it is possible, but it lacks the effort that seems to unify people engaged in semiverbal and non-verbal communication. This was a surprising finding to me since in my own country I rarely use any form of communication other than verbal. I had always assumed that it was the most effective. And perhaps it is in a native environment, but in a foreign one semi-verbal is much better.

Of course, some tend to criticize the value of limited verbal communication alone. Nevertheless, we can conclude that, paradoxically, the language barrier contributes to the feeling of togetherness in the international peer group of unorganized youth tourism in Europe.

\section{Exchange of Addresses}

The high degree of mobility gives the meetings a transitory character. Should the magic togetherness definitely end with the farewell? A seemingly practical answer to this question is the swapping of addres- 
ses: "In the end, we all exchanged addresses and swore to meet one another again some day." This way, one is able to uphold the feeling of togetherness in the very moment of parting company. That is why the exchange of addresses is common practice. The ritual is fulfilled in the act of exchanging the addresses. A later use of the address is an exception. Letters are seldom written and even more rarely answered. Sometimes, addresses collected are used during later journeys or handed to friends planning a trip. The outcome of such a pragmatic use of a ritualistic broken pledge is uncertain.

\section{Trains and Railway Stations}

As for the places where young tourists meet and where we could meet them, the compositions and interviews of the first study drew our attention to trains and railway stations as important venues. It turned out that this is due to the system of Inter-rail (available to young people from continental countries) and Eurail passes (for tourists from overseas countries). In a second step of research on unorganized youth tourism in Europe this mode of travel was explored (Schönhammer, $1987 ; 1989)$. This time the field work was carried out mostly in railway stations and trains. Methods used were asking travelers to sketch a rough map of Europe and to indicate the route followed so far and what was still planned, interviews, questionnaires with open-ended questions, and participant observation. The respondents to the questionnaire consisted of 160 users and 55 non-users of Inter-rail/Eurail passes.

\section{Stressful Restlessness}

The sketch maps of travel routes show that, on average, Inter-rail travelers covered $6,000 \mathrm{~km}$ and visited 12 locations, whereas the average for young people of the comparison group was $2,700 \mathrm{~km}$ and seven locations. It is worth noting that only $20 \%$ of the Inter-railers cover more than $7,000 \mathrm{~km}$ (the record in the sample was $13,500 \mathrm{~km}$ ). This fact and statements by the interviewees prove that for the majority of the Inter-railing travelers the mere possibility of free movement in the European network of railways is more important than a pricedistance calculation for a planned route. In any case, the average of $6,000 \mathrm{~km}$ covered and 12 locations visited seems to be enough to make the journey rather stressful. Besides "unfriendly people" (i.e., adult inhabitants of the visited countries) and "problems of finding accommodation," "discomfort of the train journey" is one of the most frequently mentioned negative experiences of the trip. Each of these categories occurs in $24 \%$ of the questionnaires of the Inter-railers. In the comparison group "unfriendly people" is also a frequently reported frustration (29\%), but complaints about "discomfort of the train journey" and "problems of finding accommodation" are seldom mentioned (6\% for each category). 
Inter-railing tourists not only cover larger distances by train. They often try to sleep on trains and in railway stations. The typical atmosphere of railway stations is appreciated by many of the young people in the comparison group $(43 \%)$, but it does not attract many of the young people in the Inter-railing group (11\%). The whole atmosphere of constant arrival and departure has no attraction for someone who is using the railway station as surrogate accommodation. However, this predicament contributes to the sociability of the international peer group, referred to above: "There is almost a feeling of solidarity-we are in this together, for better or for worse."

There is another way the young people of the Inter-railing group and those of the comparison group differ. Only $14 \%$ of the Inter-railers like hitchhiking as against $38 \%$ of the comparison group. They fear the insecurities and uncertainties of hitchhiking. Insecurity and the fear of isolation also seem to be anticipated by the decision to travel with a friend or a couple of friends-only $8 \%$ of the female and $16 \%$ of the male Inter-railers travel alone as against $18 \%$ and $25 \%$ in the comparison group. Young people from the local peer group (back home) take part in the adventure of independent mobility. Thus the risks associated with free movement in a strange space are reduced from the beginning.

Buying the Inter-rail or Eurail pass is a magic conquest of Europe. This is very attractive for novices in independent travel: "Many first-time travelers are imperialists at heart: they yearn for territory," as the American Let's go Europe states critically. The attempt to keep up with the imaginary appropriation of geographical space results in a stressful restlessness. Nevertheless, the experience is fascinating, even if many travelers confess that next time they will try to make a less stressful use of the pass. Next time? Fewer than $10 \%$ of the Inter-railing young people gave an affirmative answer to the question of whether they had traveled in this way before. Thus we can conclude that the Inter-rail pass is extremely attractive for the first venture into unorganized independent travel, but that it reinforces a restlessness that is characteristic of novices in independent travel. The pass is not very attractive for later trips. Relaxation, a typical aim of adult/family tourism, is looked on differently after the experience of an Inter-rail tour.

\section{Cross-cultural Aspects}

Both studies involved young people from different European and overseas countries. The differences between the national groups have been bracketed so far. One of these differences is mentioned and discussed, though only briefly.

To begin with, a remark must be made about the problem of identifying cultural/national differences. Experiences with "people from foreign nations and cultures" were explicitly asked for in the first study. The 
interviews and compositions showed that this task evokes a fundamental ambivalence. On the one hand knowledge of the mentality of foreign people is valued. Such knowledge proves that one is able to understand different cultural patterns. This ability of the experienced traveler is supposed to contribute also to reflecting on his or her own cultural/national identity. On the other hand, an enlightened person holds a critical view of the judgments made about foreigners as being perhaps no more than inadmissible generalizations about a whole group of persons. This ambivalence is rooted in fundamental values of modern Western culture. Therefore, it is met not only in the thoughts of (young) tourists, but also in the research programs of social scientists (e.g., in the study of prejudice; for further discussion of this controversial topic see Bateson, 1972 and Schönhammer, 1987).

When the two investigations were under way, a relatively large number of young people from North America traveled with Eurail passes. This may be one of the reasons why the specific mentality of young Americans was often mentioned by other tourists. There are two complementary judgments about them that keep on recurring: "They are very open" and "They are very superficial." The "easygoing American" is experienced on the one hand as a catalyst for the togetherness in the international peer group, but on the other hand it is this same element that is evaluated as a lack of affective engagement. The different meanings of "openness" as well as "friendship" for Europeans and for Americans have been described before, for example, by Lewin, shortly after his emigration from Germany to the United States (Lewin, 1935; cf. Erikson, 1950). The "easygoing" interpersonal style of the young Americans is sometimes reflected in the compositions of the American travelers in the sample: Americans tend, for example, to comment on the language barrier with a theory of "smiling-the international language."

\section{Conclusions}

Young people independently traveling through the European network of youth hostels and railways constitute, as described above, an international peer group that provides a feeling of familiarity among a world of strangers. They find this fascinating. Looked at dispassionately and from some distance, however, the evaluation of this companionship with numberless others seems to be that less could have been more. The Inter-rail/Eurail passes provide the possibility of freedom (and relative security) of movement in many European countries. This offer meets the adolescent desire for independent appropriation of the world. Young travelers' fascination with freedom of movement is transformed into stress when they realize the many possible destinations and routes offered by the Inter-rail/Eurail pass. Again the question arises: could less have been more? 
Seen in this light, the form of youth tourism described above is not only a step in the transition to adulthood, but also a step in a kind of tourist career. Pearce (1988) suggested a career ladder based on Maslow's hierarchy of needs (from physiological needs like relaxation to security, love and belongingness, and finally self-actualization). The career step that is hinted at in our findings does not fit in this ladder. Relaxation, for example, as a typical aim of adult tourism, becomes attractive after the stressful realization of higher order needs. Leaving behind juvenile forms of tourism is therefore not just a mark of "progress," but also a loss. After adopting adult forms of tourism, there may well be nostalgia for the feeling of solidarity in the international peer group.

\section{References}

Bateson, G. (1972). Steps to an ecology of the mind. New York: Chandler.

Csikszentmihalyi, M., \& Larson, R. (1984). Being adolescent. New York: Basic Books.

Erikson, E.H. (1950). Childhood and society. New York: Norton.

Goldberg, T. (1969). The automobile: A social institution for adolescents. Environment and Behavior, 1, 157-185.

Lewin, K. (1935). A dynamic theory of personality. New York: McGraw-Hill.

Lewin, K. (1951). Field theory in social science (D. Cartwright, Ed.). New York: Harper.

Pearce, P.L. (1988). The Ulysses factor. New York: Springer-Verlag.

Schönhammer, R. (1987). Jugendliche Europa-Touristen. Starnberg: Studienkreis für Tourismus e.v.

Schönhammer, R. (1989). Interral. Zum Verhalten und Erleben jugendlicher Touristen. Zeitschrift für Sozialisationsforschung und Erziehungssoziologie (ZSE), 9(1), 59-76.

Schönhammer, R. (1991). In Bewegung (In motion). München: Quintessenz. 